www.jmscr.igmpublication.org

Impact Factor 5.244

Index Copernicus Value: 5.88

ISSN (e)-2347-176x ISSN (p) 2455-0450

crossref DOI: _http://dx.doi.org/10.18535/jmscr/v4i3.08

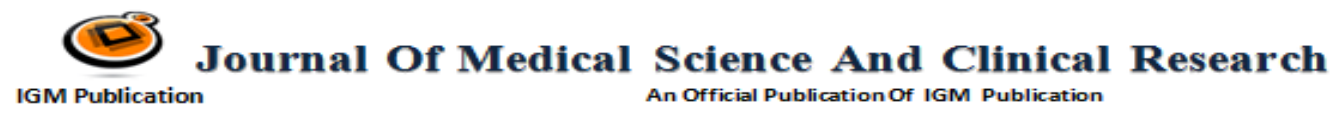

\title{
Awareness of HPV, Cervical Cancer and Preventive Measures: A Questionnaire survey from Hyderabad, India
}

\author{
Authors \\ A Ashwini, Nagavalli Sreerangam, N.V.R.Murty, K Aparna \\ Dept of Obstetrics and Gynaecology, St Theresa's Hospital Hyderabad, India \\ Corresponding Author \\ Dr Aparna Kappaganthu \\ Head of the Department of Obstetrics and Gynecology \\ St Theresa's Hospital. Hyderabad, India
}

\begin{abstract}
Aim: This study aimed to cross-sectionally examine women's' awareness and understanding of HPV infection, its role in causing cervical cancer and preventative measures available in an urban Indian setting.

Methodology: A convenience sample of 1000 women (between 20 and 50 years of age) who attended the Gynecology OP department of an urban general hospital in Hyderabad, India was invited to complete a questionnaire survey. The29-item knowledge and attitudes questionnaire assessed subjects' awareness of HPV infection, its relationship to cervical cancer and the availability \& use of cervical smears and vaccines to prevent the same. The data was systematically collated and analyzed using descriptive statistics.

Results \& Conclusions: Only 31.9\% of the sample had an awareness of HPV infections. Most of those who had this awareness, knew that it could cause cancer but only a fifth knew that HPV was transmitted sexually. Less than a third had some awareness of cervical screening and only $25 \%$ knew about HPV vaccination. $62 \%$ of the subjects were prepared to undergo cervical screening, with the remaining refusing due to cost, embarrassment, fear or pain. Finally, awareness was mainly obtained through various media sources, and was higher amongst subjects who were more literate and from upper socio-economic backgrounds.

The implications of these findings to focusing and planning public awareness campaigns-perhaps through the use of media resources is discussed.
\end{abstract}

\section{INTRODUCTION}

Cervical cancer is the second most common cancer in women. A large majority (over 90\%) of the global burden of this condition lies in developing countries (Hughes 2009). The past few decades have seen a revolution in our understanding of cervical cancer, particularly in relation to its early detection through cervical smear tests and (more recently) the role of the
Human Papilloma Virus (HPV) in its etiology. HPV infection is now known as an important cause of cervical cancer, and effective vaccines have been developed to prevent the same (Marlow, Waller, \& Wardle, 2007; Marshall, Ryan, Roberton, \& Baghurst, 2007; Wong, 2009). Although both cervical screening and HPV vaccines have the potential to prevent cervical cancer, their effectiveness and efficiency is 
limited by low levels of awareness and poor uptake- this despite the existence of a number of guidelines and recommendations (Conroy, et al 2009; Chao et al 2009).A number of studies have identified low levels of knowledge and awareness of HPV, cervical screening and HPV vaccination across the developing world (Rama et al 2010; Imam et al 2008; Al-Dubai et al 2010; Aswathy et al 2012; Ali et al 2010). Similarly, studies have also explored patients', doctors' and family members' attitudes and beliefs about HPV vaccination that might influence acceptability of the vaccine (Chan et al 2012; Wong et al 2013, Zimet 2006, Lenselink et al 2008).

The present study aims to cross-sectionally explore women's' awareness and understanding of HPV infection, its role in causing cervical cancer and preventative measures available in an urban Indian setting. It is hoped that this will help in establishing a baseline upon which future public health measures could be planned and monitored against.

\section{METHODOLOGY}

The study was conducted at St Theresa's Hospital, Hyderabad, India. A convenience sample of 1000 women (between 20 and 50 years of age) who attended the Gynecology OP department of the hospital from March 2010 to March 2012 was invited to complete a paper survey for this study. Consenting subjects were asked to complete a 29item knowledge and attitudes questionnaire to assess their awareness of HPV infection, its relationship to cervical cancer and the availability $\&$ use of cervical smears and vaccines to prevent the same.

Data was systematically collated and analyzed using descriptive statistics.

\section{RESULTS}

The mean age of the sample was 26 years. $21 \%$ of the subjects were either illiterate or had attended primary school, while $40 \%$ had completed secondary or pre-university education, and a further $39 \%$ were graduates or post-graduates. The majority of the subjects belonged to a middle $(44.9 \%)$ or lower socio-economic (27\%) background. Most were married (95\%), with the mean age at marriage being 20 years. $48 \%$ of the subjects lived in joint families and $52 \%$ lived in nuclear families. For those who had children, the mean age at childbirth was 21 years.

\section{Awareness of HPV infection and its spread/ consequences}

Three hundred and nineteen subjects (31.9\%) reported being aware of HPV infections. There were no significant differences in the level of awareness across different age ranges- although fewer older people reported being aware of this infection (21\% of subjects above 40 years of age). Subjects who were better educated $(76.79 \%)$, and from an upper socio-economic class $(85.71 \%)$ reported being more aware of HPV infections, and was statistically significant when compared to subjects who were less literate and from middle/ lower socio-economic classes $(\mathrm{p}<0.05)$. Amongst those who were aware of HPV infections, 193 $(60.5 \%)$ had heard about it from various media sources.

Of the 319, $272(85.3 \%)$ subjects were aware that HPV infection could cause cancer, 41 (12\%) were aware that it could cause genital warts and 6 $(1.8 \%)$ knew that it could cause both.. The level of awareness of the physical complications of HPV infection was higher amongst the more literate subjects than others $(\mathrm{p}<0.05)$.

Only $21 \%$ of the study population knew that HPV is transmitted sexually, a larger number of subjects from the upper socio-economic classes had this awareness (55\%). With respect to cure, about $30 \%$ of the subjects felt that this could be cured, and that the use of condoms would prevent this infection. This was also more in women from an upper social class.

\section{Awareness of risk and prevention}

Based upon their awareness and understanding of HPV, $26 \%$ of the sample felt themselves to be at risk of the same, while the remaining gave 'don't 
know' responses. The majority of the latter had poor awareness of HPV, while most (22\%) those who perceived themselves to be at risk were from an upper socio-economic class.

Only $28 \%$ of the study group had some awareness of cervical screening (cervical smear test) and its role in early detection of cervical cancer. The majority of those who had such awareness were from an upper socio-economic class and were more literate than those who did not have such awareness- both these findings were statistically significant.

After it was explained to them, only $62 \%$ of the study group were prepared to undergocervical screening. Financial reasons (39\%), embarrassment (22\%), fear (22\%) and pain (17\%) accounted for the reasons to refuse cervical screening. Further, only 41 subjects $(4.1 \%)$ had previously been screened using a cervical smear test.

\section{Awareness of HPV vaccination}

Most of the subjects had good awareness of vaccinations in general (99.6\%) and $98.6 \%$ received vaccines of some description in the past. However, only $25 \%$ of the subjects had an awareness of the availability of HPV vaccination. Younger (20-29 years old) and literate (graduates and higher) subjects had better awareness of the existence of the HPV vaccine than older and lessliterate subjects. Similarly, a higher proportion of subjects $(75 \%)$ from an upper socio-economic class had an awareness of the HPV vaccine than those from a middle $(8 \%)$ or lower $(0 \%)$ class background.

The knowledge regarding HPV vaccination like eligibility, national recommendations, advantages, and administration during postpartum period was also proportionately higher amongst subjects from more literate and upper socio-economic backgrounds.

\section{DISCUSSION}

This study was conducted in an urban General hospital setting in Hyderabad, India. The hospital provides subsidized medical care to a wide catchment of working class people from a predominantly lower and middle socio-economic background. Subjects $(n=1000)$ were recruited from the walk-in Outpatient clinics of the Gynecology department. The large sample size was felt to be a strength of the study and as such, the sample was felt to be generally representative of an urban care-seeking primary care population in South India, and the findings are therefore likely to be generalizable to them.

The study was designed as a cross-sectional survey using a 29-item questionnaire that elicited the respondents' awareness and attitude towards the study topics. This however meant that subjects' responses could not be explored in detail, and could be an area for future studies to consider to gain a better understanding of the respondents' attitudes towards cervical screening and HPV vaccination in India.

To summarize the findings from our study, only $31.9 \%$ of the sample had an awareness of HPV infections. Most of those who had this awareness, knew that it could cause cancer but only a fifth knew that it was transmitted sexually. Less than a third had some awareness of cervical screening and only a fourth knew about HPV vaccination. Only $62 \%$ were prepared to undergo screening, with the remaining refusing due to cost, embarrassment, fear or pain. Finally, awareness was mainly obtained through various media sources, and was higher amongst the more literate and those from upper social backgrounds.

Studies from other developing countries suggest a higher level of awareness of HPV (range from 61$78 \%$ ) than in our study. Awareness of its relationship to cervical cancer was similar to AlDubai's findings from Malaysia, but much lower than Ali's study in Pakistan, and higher than Rama's findings from Brazil (Rama et al 2010;AlDubai et al 2010;Ali et al 2010).Awareness of cervical screening to prevent cancer was lower than in the Brazil study, but higher than in Imam's study in Pakistan. Finally, awareness of the existence of a preventive HPV vaccine was 
somewhat similar to Al-Dubai's findings from Malaysia.

Put together, the results highlight an urgent need to build a focused awareness campaign around HPV, cervical screening and HPV vaccinationthese will not only have a significant impact on alleviating individual suffering but will also go a long way in reducing the burden of cervical cancer in India. Given that literacy, improvements in socio-economic situation and media - all appear to be associated with better awareness (and acceptability) of these preventative measurespublic health measures could be usefully focused on these aspects too.

\section{CONCLUSIONS}

Our study found a comparable, but low level of awareness about HPV infections, its consequences and availability of preventative measures in an urban female working class population in Hyderabad, India. The study has implications for planning and focusing on public health measures to improve this awareness (perhaps through media-based campaigns)- thus addressing potential barriers to the uptake of these preventive measures.

\section{REFERENCES}

1. Al-Dubai SAR, Alshagga MA, Al-Naggar RA, Al-Jashamy K, Baobaid MF, Tuang $\mathrm{CP}$, Kadir SYA. Knowledge, attitudes and barriers for human papilloma virus (hpv) vaccines among Malaysian women. Asian Pacific Journal of Cancer Prevention. 2010, 11:887-892

2. Ali SF, Ayub S, Manzoor NF, Azim S, Afif M, et al. Knowledge and Awareness about Cervical Cancer and Its Prevention amongst Interns and Nursing Staff in Tertiary Care Hospitals in Karachi, Pakistan. PloS ONE; 2010: 5(6): e11059. Doi:10.1371/journal.pone.0011059

3. Aswathy S, Quereshi MA, Kurian B, and K. Leelamoni. Cervical cancer screening: Current knowledge \& practice among women in a rural population of Kerala, India. Indian J Med Res. 2012; 136(2): 205-210.

4. Chan ZC, Chan TS, Ng KK, Wong ML. A systematic review of literature about women's knowledge and attitudes toward human papillomavirus (HPV) vaccination. Public Health Nursing 2012; 29(6): 481489.

5. Chao, C., Slezak, J. M., Coleman, K. J., \& Jacobsen, S. J. Papanicolaou screening behavior in mothers and human papilloma virus vaccine uptake in adolescent girls. American Journal of Public Health 2009; 99(6), 1137-1142.

6. Conroy, K., Rosenthal, S. L., Zimet, G. D., Jin, Y., Bernstein, D. I., Glynn, S., et al. Human papillomavirus vaccine uptake, predictors of vaccination, and self-reported barriers to vaccination. Journal of Women's Health 2009; 18(10), 16791686.

7. Hughes, C. Cervical cancer: Prevention, diagnosis, treatment and nursing care. Nursing Standard 2009; 23(27), 48-56.

8. Imam SZ, Rehman F, Zeeshan MM, Maqsood B, Asrar S, Fatima N, Aslam F, Khawaja MR. Perceptions and practices of a pakistani population regarding cervical cancer screening. Asian Pac J Cancer Prev. 2008;9:42-44.

9. Lenselink $\mathrm{CH}$, Gerrits MM, Melchers WJ, Massuger LF, van Hamont D, Bekkers RL. Parental acceptance of Human Papillomavirus vaccines. Eur J Obstet Gynecol Reprod Biol. 2008 Mar;137(1):103-7.

10. Marlow, L. A. V., Waller, J., \& Wardle, J. Parental attitudes to pre-pubertal HPV vaccination. 2007; Vaccine, 25(11), 19451952.

11. Marshall, H., Ryan, P., Roberton, D., \& Baghurst, P. A cross-sectional survey to assess community attitudes to introduction of human papillomavirus vaccine. 
Australian and New Zealand Journal of Public Health, 2007; 31(3), 235-242.

12. Rama CH, Villa LL, Pagliusi S, Andreoli MA, Costa MC, Aoki AL, Longatto-Filho A, Eluf-Neto J Awareness and knowledge of HPV, cervical cancer, and vaccines in young women after first delivery in São Paulo, Brazil - a cross-sectional study. BMC Women's Health 2010, 10: 35 http://www.biomedcentral.com/1472$6874 / 10 / 35$

13. Wong, L. P. Preventing cervical cancer through human papilloma virus vaccination: Perspective from focus groups. Journal of Lower Genital Tract Disease, 2009; 13(2), 85-93.

14. Wong MC, Lee A, Ngai KL, Chor JC, Chan PK. Knowledge, attitude, practice and barriers on vaccination against human papillomavirus infection: a cross-sectional study among primary care physicians in Hong Kong. PLoS One. 2013 Aug 21; $8(8)$.

15. Zimet GD. Understanding and overcoming barriers to human papillomavirus vaccine acceptance. Curr Opin Obstet Gynecol. 2006 Feb;18 Suppl 1:s23-8. 